\title{
Microstructures and Recording Mechanism of Mo/Si Bilayer Applied for Write-Once Blue Laser Optical Recording
}

\author{
Sin-Liang Ou, ${ }^{1}$ Kuo-Sheng Kao, ${ }^{2}$ Han-Feng Chang, ${ }^{3}$ Tsung-Shine Ko, ${ }^{4}$ and Chin-Yen Yeh ${ }^{3}$ \\ ${ }^{1}$ Department of Materials Science and Engineering, National Taiwan University, Taipei 106, Taiwan \\ ${ }^{2}$ Department of Computer and Communication, SHU-TE University, Kaohsiung 824, Taiwan \\ ${ }^{3}$ CMC Magnetics Corporation, Taoyuan 333, Taiwan \\ ${ }^{4}$ Department of Electronic Engineering, National Changhua University of Education, Changhua 500, Taiwan
}

Correspondence should be addressed to Sin-Liang Ou; odibear@gmail.com

Received 14 December 2013; Revised 22 February 2014; Accepted 24 February 2014; Published 7 April 2014

Academic Editor: Sheng-Po Chang

Copyright (C) 2014 Sin-Liang Ou et al. This is an open access article distributed under the Creative Commons Attribution License, which permits unrestricted use, distribution, and reproduction in any medium, provided the original work is properly cited.

\begin{abstract}
$\mathrm{Mo} / \mathrm{Si}$ bilayer thin films were grown by magnetron sputtering and applied to write-once blu-ray disc (BD-R). The microstructures and optical storage properties of $\mathrm{Mo} / \mathrm{Si}$ bilayer were investigated. From the temperature dependence of reflectivity measurement, it was revealed that a phase change occurred in the range of $255-425^{\circ} \mathrm{C}$. Transmission electron microscopy analysis showed that the as-deposited film possessed Mo polycrystalline phase. The hexagonal $\mathrm{MoSi}_{2}$ and cubic $\mathrm{Mo}_{3} \mathrm{Si}$ phases appeared after annealing at 300 and $450^{\circ} \mathrm{C}$, respectively. By measuring the optical reflectivity at a wavelength of $405 \mathrm{~nm}$, the optical contrast of Mo/Si bilayer between as-deposited and $450^{\circ} \mathrm{C}$-annealed states was evaluated to $25.8 \%$. The optimum jitter value of $6.8 \%$ was obtained at $10.65 \mathrm{~mW}$ for $4 \times$ recording speed. The dynamic tests show that the Mo/Si bilayer has high potential in BD-R applications.
\end{abstract}

\section{Introduction}

For write-once blu-ray disc (BD-R), amorphous silicon (a$\mathrm{Si}$ ) was used as a recording layer due to its advantages of low cost and easy fabrication process. However, the high crystallization temperature of $700^{\circ} \mathrm{C}$ for a-Si is a serious shortcoming, leading to a high writing power in the recording characteristics. It is well known that metal induced crystallization (MIC) can be applied to decrease the crystallization temperature of a-Si by introducing various metals [1-5]. Therefore, several metal/a-Si bilayer structures such as $\mathrm{Cu} / \mathrm{Si}$ [6], $\mathrm{Al} / \mathrm{Si}$ [7], Ni/Si [8], and $\mathrm{Cu}-\mathrm{Al} / \mathrm{Si}$ [9] have been proposed as the recording films of $\mathrm{BD}-\mathrm{R}$.

It has been reported that the crystallization temperature of a-Si in $\mathrm{Mo} / \mathrm{Si}$ multilayer films was ranging from 200 to $400^{\circ} \mathrm{C}$ [10], indicating that the $\mathrm{Mo} / \mathrm{Si}$ based films could be suitable for BD-R. Actually, Mo/Si structured mirrors have been widely studied for applications in extreme ultraviolet lithography because of their high normal incidence reflectance [11-15]. Nevertheless, it has not been found that the $\mathrm{Mo} / \mathrm{Si}$ based thin films were applied to optical recording media. In this study, we presented the Mo $(7 \mathrm{~nm}) / \mathrm{Si}(7 \mathrm{~nm})$ bilayer as the recording film of BD-R. The crystallization temperature, microstructures, and recording characteristics of this bilayer were analyzed and discussed.

\section{Experimental Procedure}

The Mo $(7 \mathrm{~nm}) / \mathrm{Si}(7 \mathrm{~nm})$ bilayer was grown on nature oxidized Si wafers and polycarbonate (PC) substrates at room temperature by magnetron sputtering using the Mo and $\mathrm{Si}$ targets. In order to apply the Mo/Si bilayer to write-once optical recording media, the multilayer of Ag reflective layer $(95 \mathrm{~nm}) / \mathrm{ZnS}-\mathrm{SiO}_{2}(35 \mathrm{~nm}) / \mathrm{Mo}(7 \mathrm{~nm}) / \mathrm{Si}(7 \mathrm{~nm}) / \mathrm{ZnS}-\mathrm{SiO}_{2}$ $(24 \mathrm{~nm})$ was fabricated on $1.1 \mathrm{~mm}$-thick PC substrate which has a track pitch of $0.32 \mu \mathrm{m}$. Afterwards, a PC transparent cover layer with $0.1 \mathrm{~mm}$ thickness was covered on the top of these layers by spin-coating. The crystallization temperature of as-deposited specimen was measured by a home-made reflectivity-temperature analyzer. The microstructures and crystal orientations of the samples before and after annealing 
TABLE 1: Dynamic test conditions.

\begin{tabular}{lc}
\hline User capacity & $25 \mathrm{~GB}$ \\
Thickness of substrate & $1.1 \mathrm{~mm}$ \\
Wavelength & $405 \mathrm{~nm}$ \\
Numerical aperture (N.A.) & 0.85 \\
Modulation code & $(1,7) \mathrm{RLL}$ \\
Track pitch & $0.32 \mu \mathrm{m}$ \\
Linear velocity & $4.92 \mathrm{~m} / \mathrm{s}(1 \times), 19.68 \mathrm{~m} / \mathrm{s}(4 \times)$ \\
Recording format & On groove \\
\hline
\end{tabular}

were characterized by transmission electron microscopy (TEM). Relationship between reflectivity and wavelength was measured by means of a UV-VIS-NIR spectrophotometer (Perkin-Elmer Lambda 900). To study the diffusion characteristic of $\mathrm{Mo} / \mathrm{Si}$ bilayer, the element concentration depth profiles of the as-deposited and annealed samples were analyzed using Auger electron spectrometer (AES). The recording characteristics of the discs were evaluated by a dynamic tester (ODU-1000, PULSTEC), and the testing conditions were shown in Table 1. The wavelength of the laser beam is $405 \mathrm{~nm}$ and the numerical aperture (N.A.) of the objective lens is 0.85 . The modulation code is $(1,7)$ RLL. The linear velocities of $1 \times$ and $4 \times$ recording speeds are 4.92 and $19.68 \mathrm{~m} / \mathrm{s}$, respectively.

\section{Results and Discussion}

Figure 1 exhibits the reflectivity changes as a function of temperature for the $\mathrm{Mo} / \mathrm{Si}$ bilayer at a heating rate of $20^{\circ} \mathrm{C} / \mathrm{min}$. The measured temperature was increased from room temperature to $550^{\circ} \mathrm{C}$ using a resistive heater. It can be found that the reflectivity has a decrease as the temperature heated from 255 to $425^{\circ} \mathrm{C}$. According to previous research, as the films undergo a structural transition, it could lead to the change of optical reflectivity [16]. Therefore, we choose the temperatures of 300 and $450^{\circ} \mathrm{C}$ to perform the annealing experiments and examine the microstructures of these films.

The TEM bright field image and electron diffraction pattern of the as-deposited Mo/Si bilayer are shown in Figure 2. It reveals that the as-deposited film has Mo polycrystalline phase with the grain size of $5 \mathrm{~nm}$, and the diffraction pattern rings are identified to Mo (110), Mo (200), and Mo (211). After annealing at $300^{\circ} \mathrm{C}$ for $15 \mathrm{~min}$, the grain size of $\mathrm{Mo} / \mathrm{Si}$ bilayer was enlarged and the hexagonal $\mathrm{MoSi}_{2}$ phase (h$\mathrm{MoSi}_{2}$ ) appeared, as shown in Figure 3. It is noted that the formation of Mo silicide in Mo/Si multilayers is attributed to the interdiffusion of Mo and $\mathrm{Si}$ atoms [17]. As the annealing temperature was increased to $450^{\circ} \mathrm{C}$ for $15 \mathrm{~min}$, we found that the grains can be divided into two parts, that is, the smaller grains (red circle) and larger grains with the size about 100-300 nm, as shown in Figure 4(a). The analysis of electron diffraction pattern also indicated that two phases existed in the film, one was $\mathrm{h}-\mathrm{MoSi}_{2}$ and the other was determined to be $\mathrm{Mo}_{3} \mathrm{Si}$ phase. The h-MoSi 2 phase with continuous and clear diffraction rings were contributed from the small grains. On the other hand, the discontinuous rings

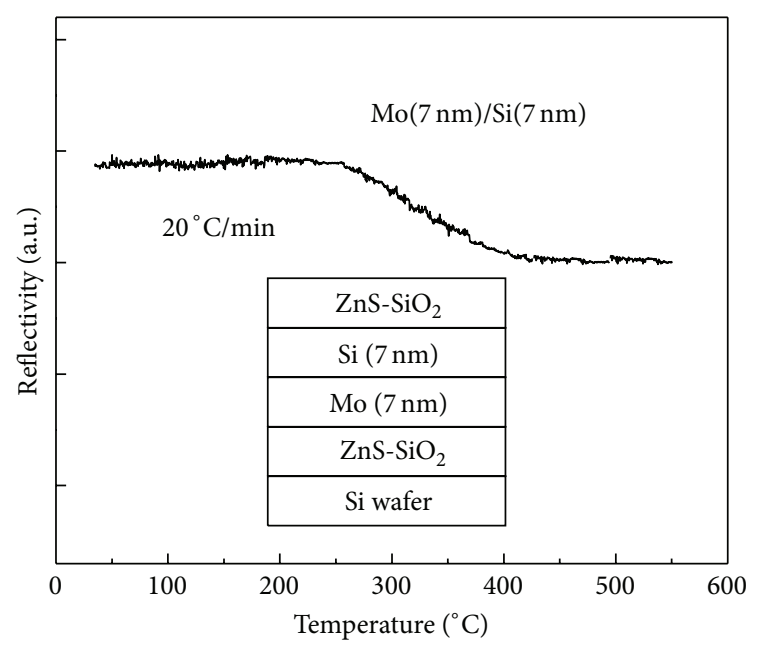

FIGURE 1: Relationship between the reflectivity and temperature of the as-deposited $\mathrm{Mo} / \mathrm{Si}$ bilayer at a heating rate of $20^{\circ} \mathrm{C} / \mathrm{min}$.

corresponding to $\mathrm{Mo}_{3} \mathrm{Si}$ phase could result from the large grains. $\mathrm{Mo}_{3} \mathrm{Si}$ phase has the cubic A15 structure such as $\beta$-W and $\mathrm{Cr}_{3} \mathrm{Si}$ [18]. This structure consists of $\mathrm{Si}$ atoms occupied the body centered cubic (bcc) positions in the unit cell and the Mo atoms form three orthogonal chains located in the [100] directions on the cube faces. To check the structure of the large grains precisely, the grain which was marked by red arrow was selected to examine by selected area electron diffraction (SAED) pattern. It shows that the large grain has $\mathrm{Mo}_{3} \mathrm{Si}$ phase with [011] zone axis, as shown in Figure 4(b). Some reports indicated that the crystallization $\mathrm{Si}$ formed in the $\mathrm{Mo} / \mathrm{Si}$ multilayer after annealing. However, there is no formation of crystallization $\mathrm{Si}$ in our results. Murarka et al. [19] have shown the relationship between $\mathrm{Mo} / \mathrm{Si}$ atomic ratio and the formation in Mo-Si thin films. While the Mo/Si atomic ratio in the film was greater than 0.5 , it revealed that only the Mo silicide including $\mathrm{MoSi}_{2}, \mathrm{Mo}_{3} \mathrm{Si}$, and $\mathrm{Mo}_{3} \mathrm{Si}_{2}$ can be observed after annealing. On the contrary, both the Mo silicide and Si crystallization appeared after annealing as the $\mathrm{Mo} / \mathrm{Si}$ atomic ratio was less than 0.5 . Consequently, the atomic ratio of $\mathrm{Mo}$ to $\mathrm{Si}$ in the interdiffused region of our annealed $\mathrm{Mo} / \mathrm{Si}$ bilayer was probably greater than 0.5 . As we calculated, the number of Mo atoms in the Mo/Si bilayer with the thickness ratio of $1: 1$ was about ten times larger than that of $\mathrm{Si}$ atoms. As a result, no crystallized Si formed in the annealed film could be ascribed to the excessive Mo atoms in the $\mathrm{Mo} / \mathrm{Si}$ bilayer. It suggested that the thickness of Mo layer should be reduced, and the Si crystallization could appear after annealing. Interestingly, we found that the large grains with $\mathrm{Mo}_{3} \mathrm{Si}$ phase had radial distribution in the film as the TEM magnification was decreased, as shown in Figure 4(c). As mentioned above, the Mo silicide consisting of $\mathrm{MoSi}_{2}$, $\mathrm{Mo}_{3} \mathrm{Si}$, and $\mathrm{Mo}_{3} \mathrm{Si}_{2}$ could appear in this study. However, there was no formation of $\mathrm{Mo}_{3} \mathrm{Si}_{2}$ phase in the annealed sample. In previous researches $[20,21]$, the activation energies of $\mathrm{MoSi}_{2}$ and $\mathrm{Mo}_{3} \mathrm{Si}$ were estimated to be 204 and $223 \mathrm{~kJ} / \mathrm{mol}$, respectively, which were close to each other. Thus, in this study, $\mathrm{MoSi}_{2}$ and $\mathrm{Mo}_{3} \mathrm{Si}$ phases were formed sequentially. 

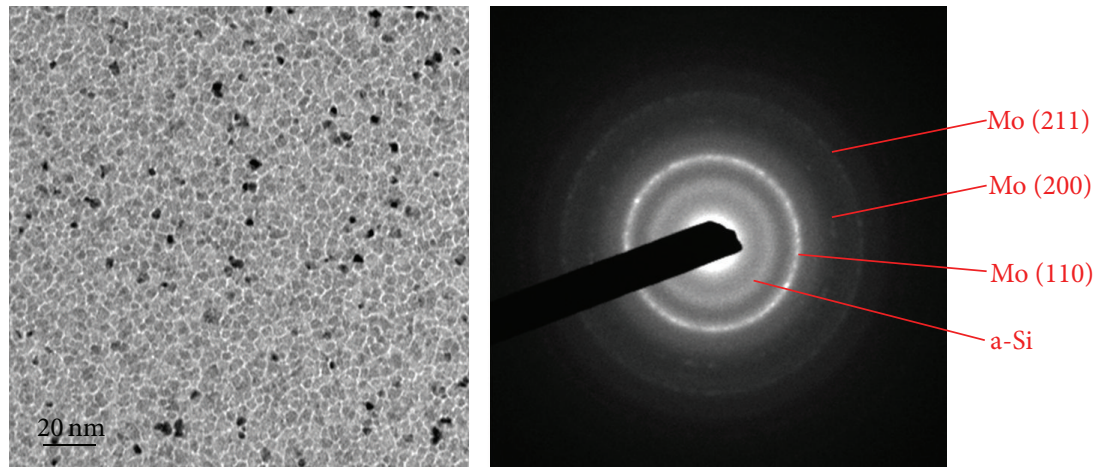

FIGURE 2: TEM bright field image and electron diffraction pattern of the as-deposited Mo/Si bilayer.
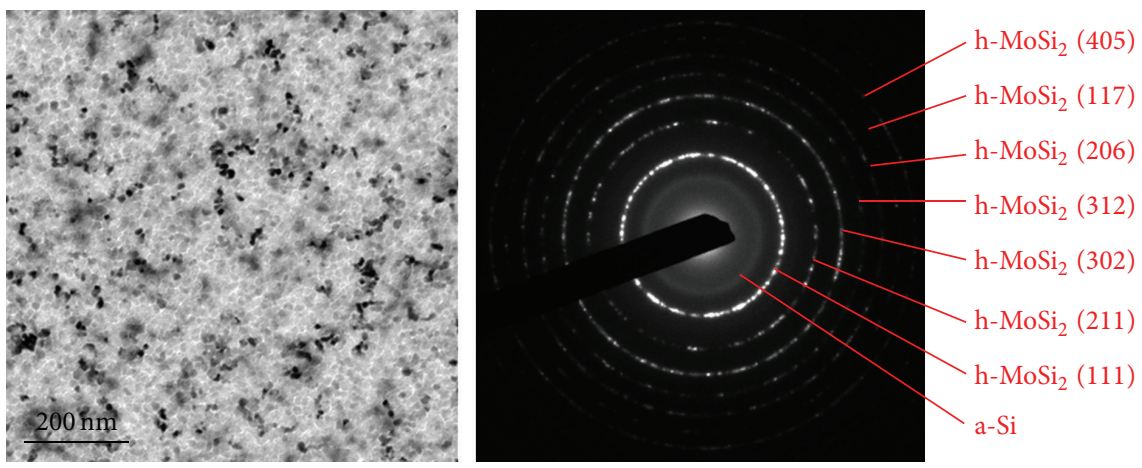

FIgURE 3: TEM bright field image and electron diffraction pattern of the $300^{\circ} \mathrm{C}$-annealed Mo/Si bilayer.

Besides, the melting temperatures of $\mathrm{MoSi}_{2}$ and $\mathrm{Mo}_{3} \mathrm{Si}_{2}$ were 1870 and $2190^{\circ} \mathrm{C}$, respectively [22]. Commonly, the higher melting temperature of material would lead to a slower rate of formation. It can be speculated that the formation of $\mathrm{Mo}_{3} \mathrm{Si}_{2}$ is more difficult than $\mathrm{MoSi}_{2}$. This could be the reason why $\mathrm{Mo}_{3} \mathrm{Si}_{2}$ phase did not appear in this study. Based on previous research [16], the difference in reflectivity resulted from the materials with different complex dielectric functions. In other words, the reflectivity of material can be changed via the phase transition process. Consequently, the decreased reflectivity of our sample (shown in Figure 1) with increasing the temperature from 255 to $425^{\circ} \mathrm{C}$ can be ascribed to the transition from Mo phase to h-MoSi ${ }_{2}$ and $\mathrm{Mo}_{3} \mathrm{Si}$ phases. Moreover, in this study, there is another factor to affect the sample reflectivity, that is, the grain feature of the sample. In Figure 2, the small and uniform grain size of as-deposited film can result in the reduction of optical anisotropy and lead to high reflectivity. However, as the $\mathrm{Mo} / \mathrm{Si}$ bilayer was annealed at $450^{\circ} \mathrm{C}$ (Figure 4 ), the nonuniform grain size would induce optical anisotropy, which caused the lower reflectivity of the annealed films. Actually, the optical isotropy and anisotropy of materials are also related to the crystal structures. This implies that $\mathrm{h}-\mathrm{MoSi}_{2}$ and $\mathrm{Mo}_{3} \mathrm{Si}$ structures could both possess optical anisotropy, leading to the decreased reflectivity.
The reflectivity spectra in the wavelength ranging from 350 to $1000 \mathrm{~nm}$ for as-deposited, $300^{\circ} \mathrm{C}$-annealed and $450^{\circ} \mathrm{C}$ annealed $\mathrm{ZnS}-\mathrm{SiO}_{2} / \mathrm{Mo} / \mathrm{Si} / \mathrm{ZnS}-\mathrm{SiO}_{2}$ samples are presented in Figure 5. For as-deposited sample, the reflectivity at a wavelength of $405 \mathrm{~nm}$ was measured to be $50.7 \%$. After annealing at 300 and $450^{\circ} \mathrm{C}$ for $15 \mathrm{~min}$, the reflectivities (at the wavelength of $405 \mathrm{~nm}$ ) of these samples were decreased to $46.2 \%$ and $37.6 \%$, respectively. The optical contrast is defined as $\left(\left(R_{1}-R_{2}\right) / R_{1}\right) \times 100 \%$, where $R_{1}$ is the reflectivity of asdeposited state and $R_{2}$ is the reflectivity of annealed state. The optical contrast (at the wavelength of $405 \mathrm{~nm}$ ) between asdeposited and $450^{\circ} \mathrm{C}$-annealed $\mathrm{Mo} / \mathrm{Si}$ films can be evaluated to $25.8 \%$. It indicates that $\mathrm{Mo} / \mathrm{Si}$ bilayer is suitable for $\mathrm{BD}-\mathrm{R}$ application.

Figures 6(a) and 6(b) show the depth profiles measured by AES for as-deposited and $450^{\circ} \mathrm{C}$-annealed $\mathrm{Mo} / \mathrm{Si}$ films, respectively. Unlike the other annealing time of $15 \mathrm{~min}$, the sample for AES measurement was only annealed for $3 \mathrm{~min}$. In Figure 6(a), it was found that the film was composed by two layers, which were Mo layer and Si layer. After annealing at $450^{\circ} \mathrm{C}$, the film was divided into three layers, that is, Mo layer, Mo-Si mixing layer, and Si layer. According to TEM observations, it can be confirmed that the Mo-Si mixing layer included the $\mathrm{h}-\mathrm{MoSi}_{2}$ and $\mathrm{Mo}_{3} \mathrm{Si}$ phases. Additionally, 

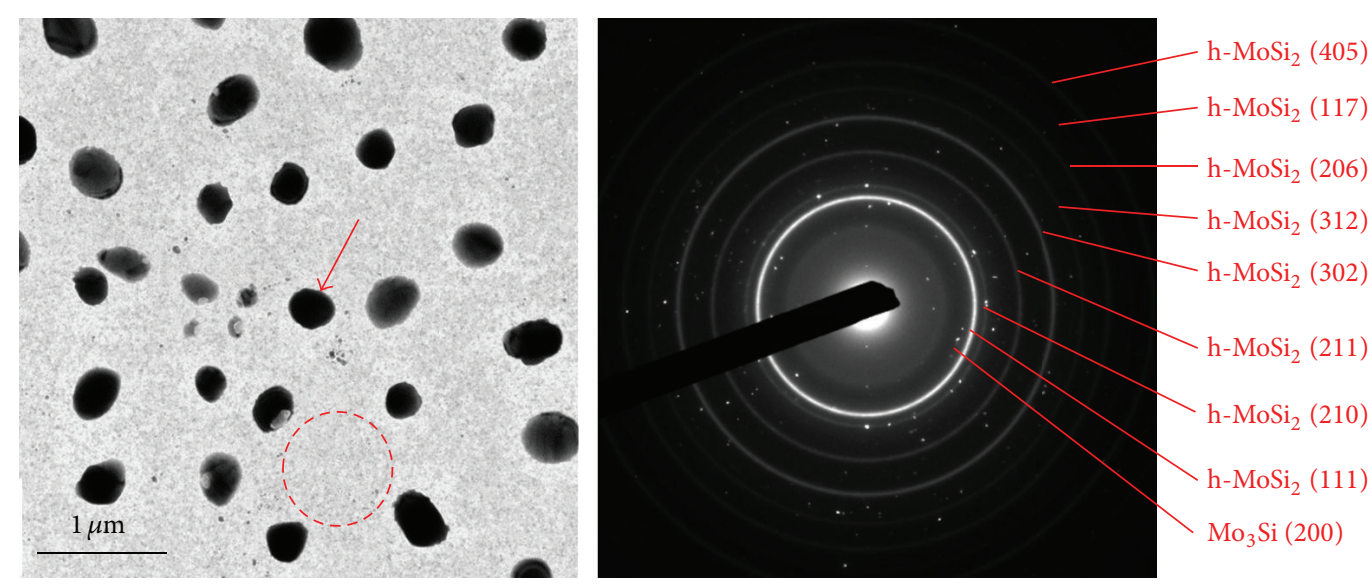

(a)

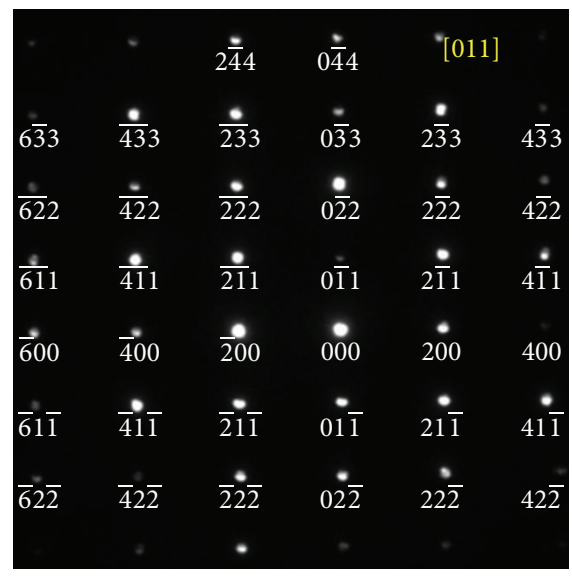

(b)

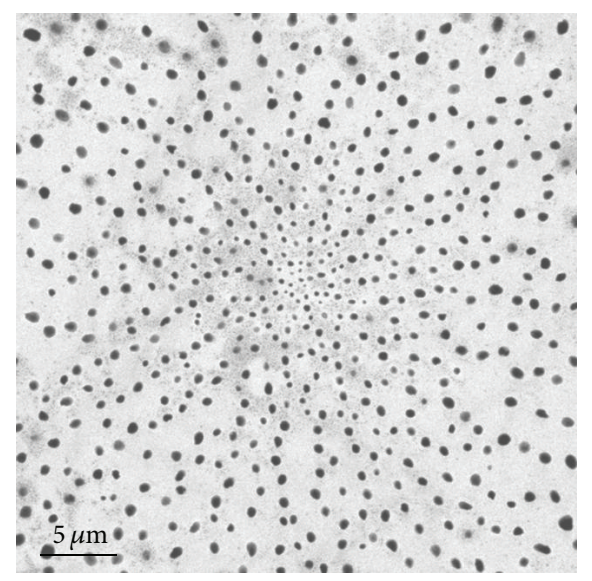

(c)

FIGURE 4: (a) TEM bright field image and electron diffraction pattern of the $450^{\circ} \mathrm{C}$-annealed Mo/Si bilayer, (b) the SAED pattern of larger grain marked by an arrow in (a), and (c) TEM image with lower magnification.

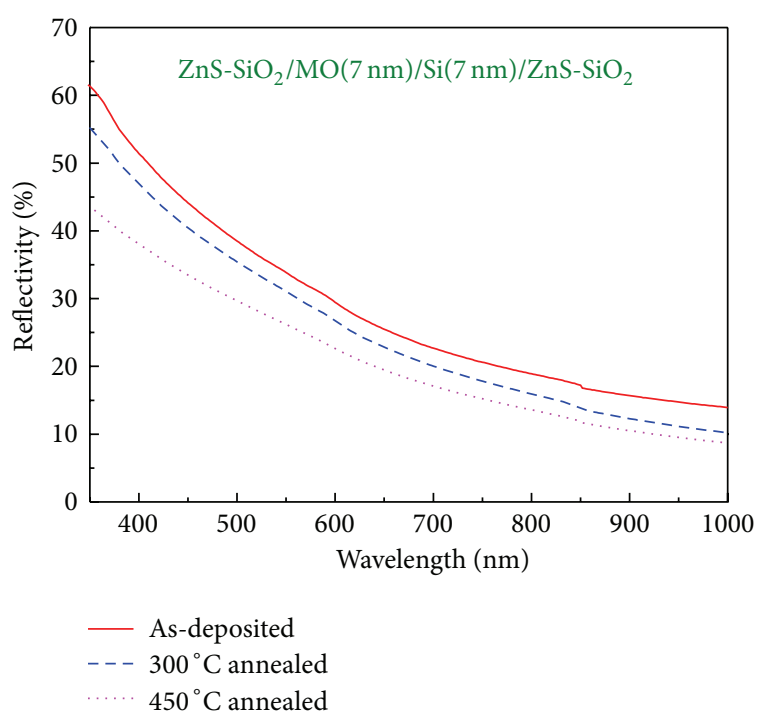

FIGURE 5: Variations of the reflectivity with wavelength for $\mathrm{Mo} / \mathrm{Si}$ films at as-deposited, $300^{\circ} \mathrm{C}$-annealed, and $450^{\circ} \mathrm{C}$-annealed states. the AES results revealed that the Mo silicide was formed by the interdiffusion of Mo and Si atoms, which was in good agreement with Holloway et al. research [17].

Figure 7 exhibits the dynamic test results that the jitter values and modulations vary with writing powers at $1 \times$ and $4 \times$ recording speeds. The suggested modulation and jitter value for $\mathrm{BD}-\mathrm{R}$ should be larger than 0.4 and lower than $7 \%$, respectively. As we can see, all measured modulations are larger than 0.4. From TEM results, the changes of structural phase and grain size uniformity in the as-deposited and annealed states would lead to high optical contrast. It probably results in enough modulation of the disc sample before and after laser writing. Experimental results show that the minimum jitter values are obtained to be $6.5 \%$ at $7.4 \mathrm{~mW}$ and $6.8 \%$ at $10.65 \mathrm{~mW}$, respectively, for $1 \times$ and $4 \times$ recording speeds. It indicates that the $\mathrm{Mo} / \mathrm{Si}$ bilayer has great potential in $\mathrm{BD}-\mathrm{R}$.

\section{Conclusion}

In summary, we have proposed a new BD-R containing $\mathrm{Mo} / \mathrm{Si}$ recording layer. Thermal analysis shows that the Mo/Si bilayer 


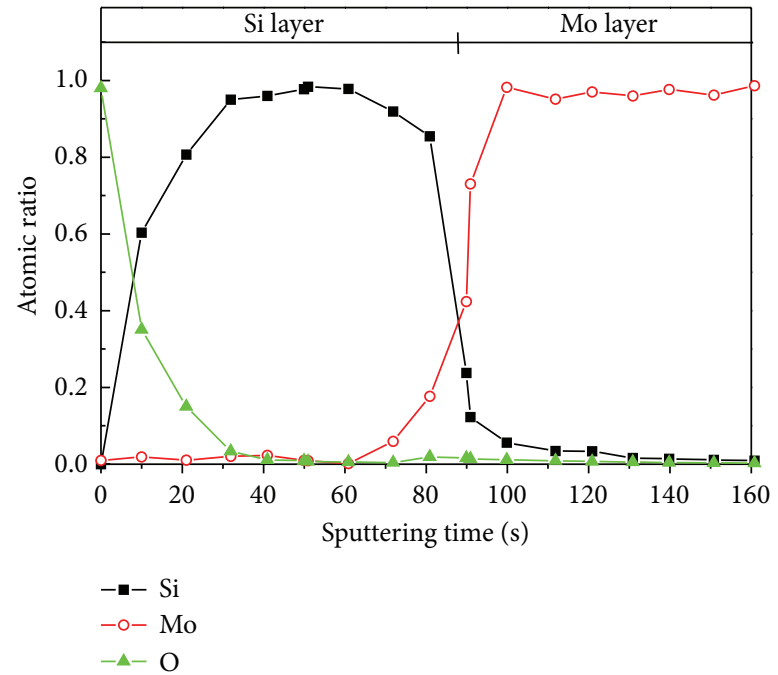

(a)

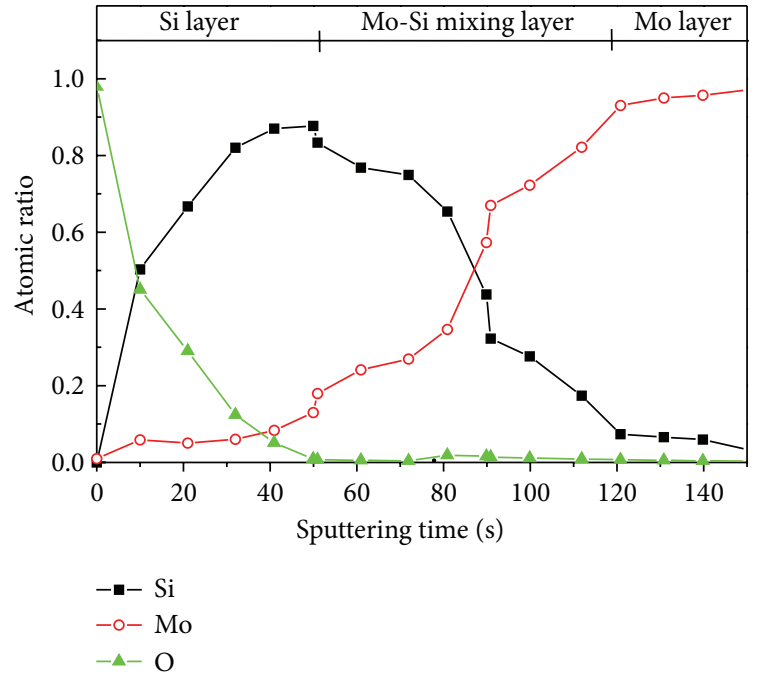

(b)

FIGURE 6: Element concentration depth profiles of (a) as-deposited and (b) $450^{\circ} \mathrm{C}$-annealed Mo/Si bilayer samples.

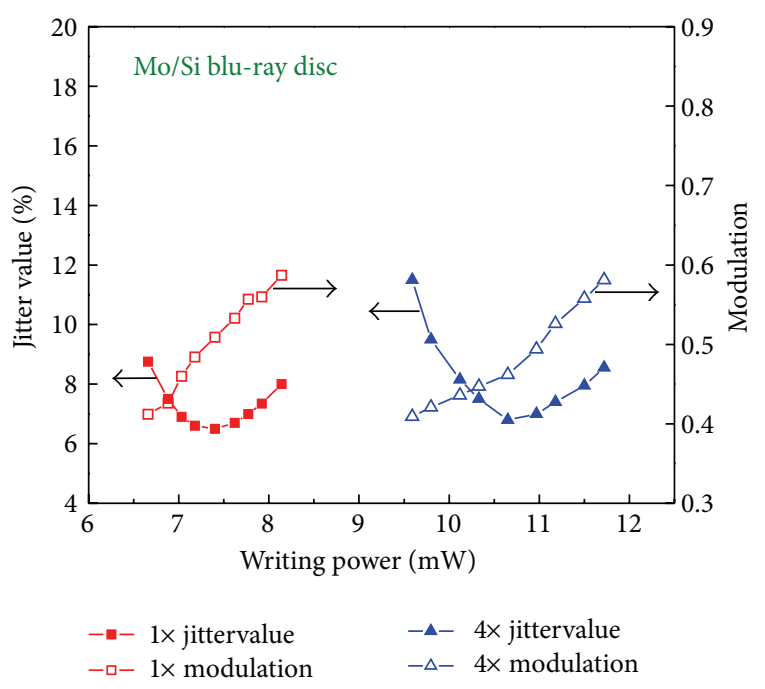

FIGURE 7: Jitter values and modulations as a function of writing power at the $1 \times$ and $4 \times$ recording speeds.

has a reflectivity change with the temperature ranging from 255 to $425^{\circ} \mathrm{C}$. The Mo phase with grain size of $5 \mathrm{~nm}$ was found in the as-deposited film. After annealing at 300 and $450^{\circ} \mathrm{C}$, the h- $\mathrm{MoSi}_{2}$ and $\mathrm{Mo}_{3} \mathrm{Si}$ were sequentially appeared. Due to the thicker Mo layer, there was no Si crystallization forming in the annealed film. The AES result confirmed that the formation of Mo silicide after annealing resulted from the interdiffusion of Mo and $\mathrm{Si}$ atoms. For $1 \times$ and $4 \times$ recording speeds, the optimum jitter values of $6.5 \%$ and $6.8 \%$ can be achieved at the recording powers of 7.4 and $10.65 \mathrm{~mW}$, respectively. Obviously, the Mo/Si bilayer has great feasibility for writeonce blue laser optical recording.

\section{Conflict of Interests}

The authors declare that there is no conflict of interests regarding the publication of this paper.

\section{Acknowledgments}

This research was supported by the National Science Council of Taiwan, Republic of China, under Contract nos. NSC 982221-E-002-053-MY3 and NSC 102-2221-E-366-002, respectively.

\section{References}

[1] L. Hultman, A. Robertsson, H. T. G. Hentzell, I. Engström, and P. A. Psaras, "Crystallization of amorphous silicon during thinfilm gold reaction," Journal of Applied Physics, vol. 62, no. 9, pp. 3647-3655, 1987.

[2] S. W. Russell, J. Li, and J. W. Mayer, "In situ observation of fractal growth during a-Si crystallization in a $\mathrm{Cu}_{3} \mathrm{Si}$ matrix," Journal of Applied Physics, vol. 70, no. 9, pp. 5153-5155, 1991.

[3] B. Bian, J. Yie, B. Li, and Z. Wu, "Fractal formation in aSi:H/Ag/a-Si:H films after annealing," Journal of Applied Physics, vol. 73, no. 11, pp. 7402-7406, 1993.

[4] C. A. Achete, F. L. Freire Jr., G. Mariotto, and E. Zangheillni, "Low-temperature silicon crystallization mediated by copper suicide formation in Cu/a-Si: H bilayers," Materials Letters, vol. 18, no. 4, pp. 218-222, 1994.

[5] M. Zou, L. Cai, H. Wang, and W. Brown, "Nano-aluminuminduced crystallization of amorphous silicon," Materials Letters, vol. 60, no. 11, pp. 1379-1382, 2006.

[6] H. Inoue, K. Mishima, M. Aoshima, H. Hirata, T. Kato, and H. Utsunomiya, "Inorganic write-once disc for high speed recording," Japanese Journal of Applied Physics 1: Regular Papers and Short Notes and Review Papers, vol. 42, no. 2, pp. 1059-1061, 2003. 
[7] Y.-C. Her and C.-W. Chen, "Crystallization kinetics of ultrathin amorphous Si film induced by $\mathrm{Al}$ metal layer under thermal annealing and pulsed laser irradiation," Journal of Applied Physics, vol. 101, no. 4, Article ID 043518, 2007.

[8] Y.-C. Her, S.-T. Jean, and J.-L. Wu, "Crystallization kinetics and recording mechanism of a-SiNi bilayer for write-once blue-ray recording," Journal of Applied Physics, vol. 102, no. 9, Article ID 093503, 2007.

[9] H.-C. Mai, T.-E. Hsieh, and S.-Y. Jeng, "Characterization of write-once blu-ray disk containing $\mathrm{Cu}-\mathrm{Al} / \mathrm{Si}$ recording layer using transmission electron microscopy," Applied Physics Letters, vol. 98, no. 9, Article ID 094103, 2011.

[10] R. S. Rosen, M. A. Viliardos, M. E. Kassner, D. G. Stearns, and S. P. Vernon, "Thermal stability of Mo/Si multilayers," in Multilayer Optics for Advanced X-Ray Applications, vol. 1547 of Proceedings of SPIE, pp. 212-220, 1991.

[11] J. M. Freitag and B. M. Clemens, "Stress evolution in $\mathrm{Mo} / \mathrm{Si}$ multilayers for high-reflectivity extreme ultraviolet mirrors," Applied Physics Letters, vol. 73, no. 1, pp. 43-45, 1998.

[12] N.-W. Pu, J. Bokor, S. Jeong, and R.-A. Zhao, "Picosecond ultrasonic study of $\mathrm{Mo} / \mathrm{Si}$ multilayer structures using an alternatingpump technique," Applied Physics Letters, vol. 74, no. 2, pp. 320322, 1999.

[13] E. J. Takahashi, Y. Nabekawa, and K. Midorikawa, "Low-divergence coherent soft X-ray source at $13 \mathrm{~nm}$ by high-order harmonics," Applied Physics Letters, vol. 84, no. 1, pp. 4-6, 2004.

[14] T. Mocek, B. Rus, M. Stupka et al., "Focusing a multimillijoule soft x-ray laser at $21 \mathrm{~nm}$," Applied Physics Letters, vol. 89, no. 5, Article ID 051501, 2006.

[15] Y. Ueno, G. Soumagne, A. Sumitani, A. Endo, T. Higashiguchi, and N. Yugami, "Reduction of debris of a $\mathrm{CO}_{2}$ laser-produced Sn plasma extreme ultraviolet source using a magnetic field," Applied Physics Letters, vol. 92, no. 21, Article ID 211503, 2008.

[16] E. García-García, A. Mendoza-Galván, Y. Vorobiev et al., "Optical properties of Ge:Sb:Te ternary alloys," Journal of Vacuum Science \& Technology A, vol. 17, no. 4, pp. 1805-1810, 1999.

[17] K. Holloway, K. B. Do, and R. Sinclair, "Interfacial reactions on annealing molybdenum-silicon multilayers," Journal of Applied Physics, vol. 65, no. 2, pp. 474-480, 1989.

[18] A. Misra, J. J. Petrovic, and T. E. Mitchell, "Microstructures and mechanical properties of a $\mathrm{Mo}_{3} \mathrm{Si}-\mathrm{Mo}_{5} \mathrm{Si}_{3}$ composite," Scripta Materialia, vol. 40, no. 2, pp. 191-196, 1998.

[19] S. P. Murarka, D. B. Fraser, T. F. Retajczyk Jr., and T. T. Sheng, "Cosputtered molybdenum silicides on thermal $\mathrm{SiO}_{2}$," Journal of Applied Physics, vol. 51, no. 10, pp. 5380-5385, 1980.

[20] A. A. Sharif, "High-temperature oxidation of $\mathrm{MoSi}_{2}$," Journal of Materials Science, vol. 45, no. 4, pp. 865-870, 2010.

[21] J.-K. Yoon, J.-Y. Byun, G.-H. Kim, J.-S. Kim, and C.-S. Choi, "Growth kinetics of three Mo-silicide layers formed by chemical vapor deposition of Si on Mo substrate," Surface and Coatings Technology, vol. 155, no. 1, pp. 85-95, 2002.

[22] J. Y. P. Mui, "Corrosion mechanism of metals and alloys in the silicon-hydrogen-chlorosilane system at 500 C," Corrosion, vol. 41, no. 2, pp. 63-69, 1985. 

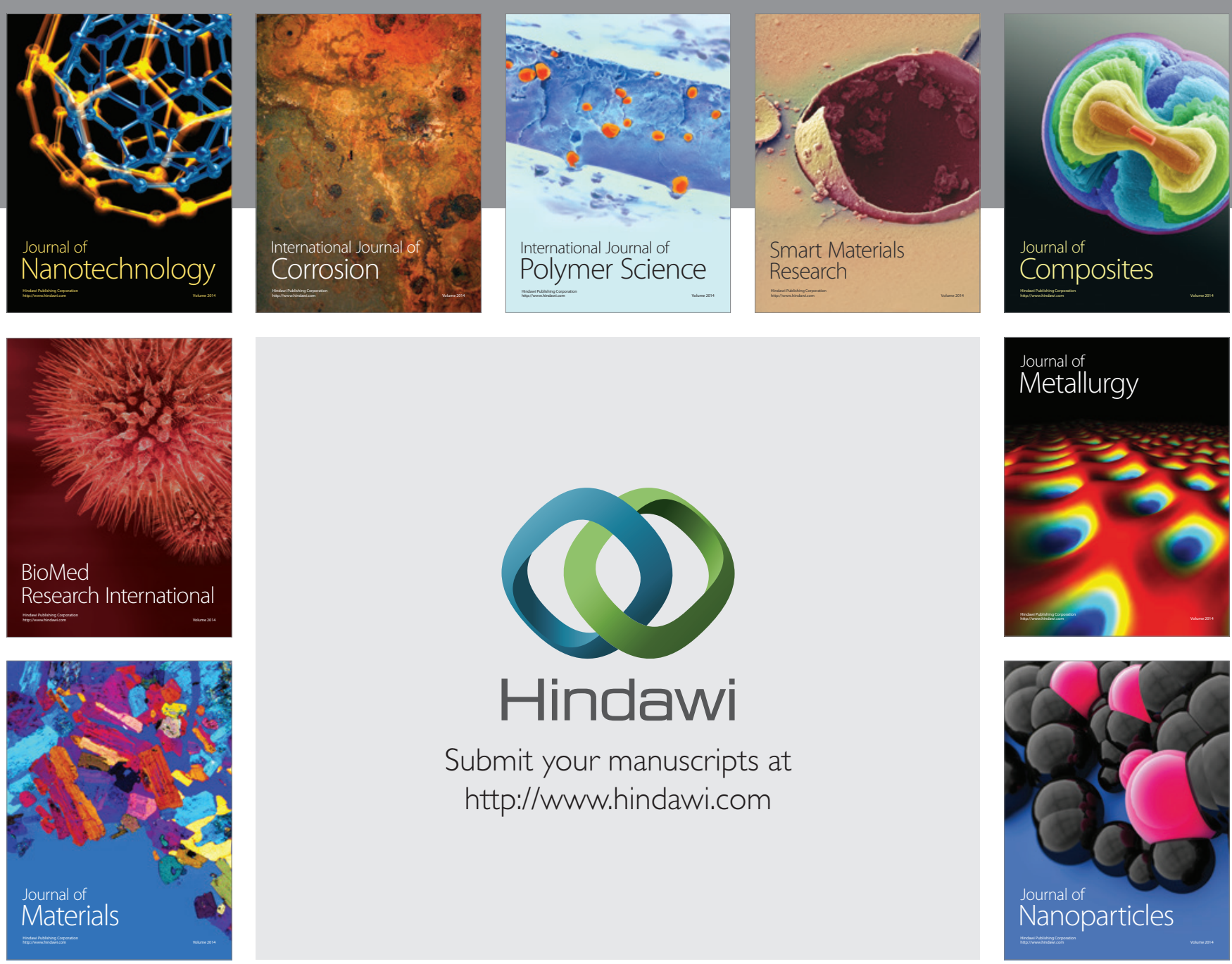

Submit your manuscripts at http://www.hindawi.com
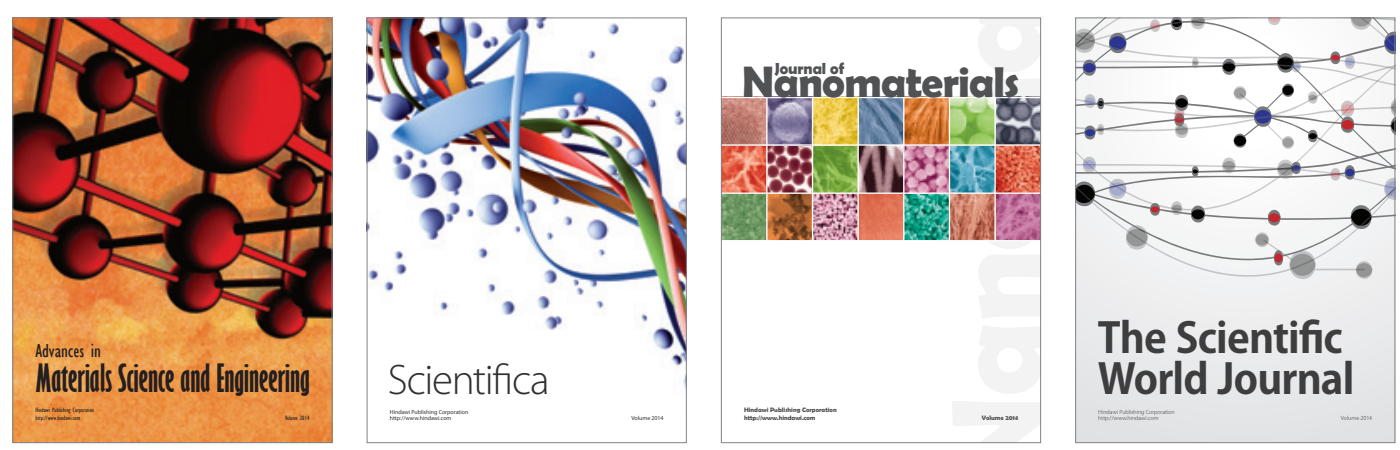

\section{The Scientific World Journal}
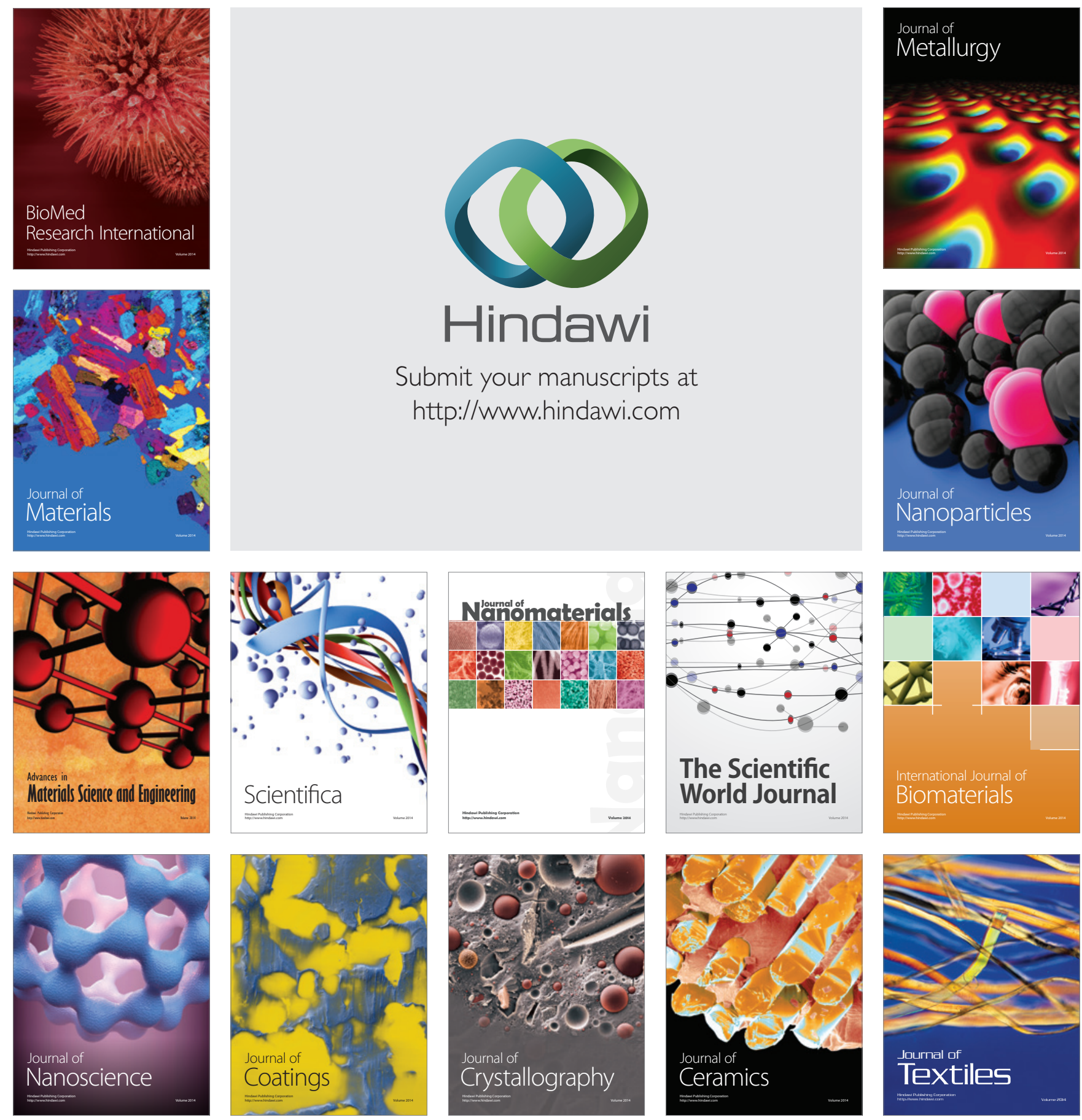